\title{
EPIDEMIOLOGIA E CONTROLE DA TRISTEZA PARASITÁRIA BOVINA NA REGIÃO SUDESTE DO BRASIL
}

\author{
EPIDEMIOLOGY AND CONTROL OF BOVINE BABESIOSIS AND \\ ANAPLASMOSIS IN SOUTHEAST REGION OF BRAZIL
}

\author{
Patrícia Macêdo Gonçalves ${ }^{1}$
}

- REVISÃO BIBLIOGRÁFICA -

RESUMO

A babesiose bovina e a anaplasmose (Tristeza Parasitária Bovina) são enfermidades transmitidas pelo carrapato Boophilus microplus e por moscas hematófagas, respectivamente, ocorrendo em caráter endêmico no Brasil, acarretando elevadas perdas econômicas na pecuária. Nesse país, observa-se uma grande variedade de fatores epidemiológicos influenciando sua ocorrência, tais como: variação climática, práticas de manejo, controle de carrapato e introdução de bovinos susceptíveis. Assim, esta revisão aborda aspectos epidemiológicos do controle da anaplasmose e da babesiose bovina do Brasil, com ênfase na região sudeste. Fatores que influenciam a instabilidade e a estabilidade enzoótica de ambas as espécies também são discutidos. As medidas de controle empregadas atualmente são: quimioprofilaxia, o uso de acaricidas para o controle do carrapato vetor B. microplus, a premunição e a vacinação.

Palavras-chave: anaplasma, babesia, epidemiologia, controle, Brasil.

\section{SUMMARY}

Bovine babesiosis and anaplasmosis are diseases transmitted by Boophilus microplus and haematophagous diptera, respectively, occurring in endemic character in Brazil, resulting in high economic loss on livestock production. In this country a wide range of epidemiological factors influencing their occurrence, such as climate variations, husbandry practices, tick control and susceptible purebreed cattle that are regularly imported to upgrade local stocks have been described. This review focuses the epidemiological control and some aspects of bovine babesiosis and anaplasmosis in Brazil, with emphasis in southeast region. Factors influencing enzootic stability and instability of both species are also discussed. The control measures employed at present are chemoprophylaxis, use of acaricides for B. microplus, premunition and vaccination.

Key words: anaplasma, babesia, epidemiology, control, Brazil.

\section{INTRODUÇÃO}

A Tristeza Parasitária Bovina é um complexo de doenças causadas por infecções com Babesia e Anaplasma, transmitidas por carrapatos (Boophilus microplus) e moscas hematófagas (Stomoxys calcitrans, tabanídeos, culicídeos), respectivamente, constituindo-se fator limitante ao desenvolvimento da pecuária nos países tropicais e subtropicais (DE VOS, 1992).

No Brasil, os principais agentes etiológicos dessa enfermidade são o Anaplasma marginale (THEILER, 1910), a Babesia bovis (BABES, 1888) e a B. bigemina (SMITH \& KILBORNE, 1893). As perdas econômicas são devido à redução na produção de leite e carne, infertilidade temporária de machos e fêmeas, custo de tratamentos (LIMA, 1991), gasto com medidas preventivas necessárias, quando se introduz animais de áreas livres em áreas endêmicas e, principalmente, devido à mortalidade.

\footnotetext{
${ }^{1}$ Aluno de Doutorado em Ciência Animal - Departamento de Medicina Veteterinária Preventiva, Escola de Veterinária, Universidade Federal de Minas Gerais, CP 567, 30161-970, Belo Horizonte, MG E-mail: pmacedog@ dedalus.lcc.ufmg.br Recebido para publicação em 27.05.98. Aprovado em 24.03.99
} 


\section{Epidemiologia da Babesiose}

Não existem trabalhos epizootiológicos no Brasil que permitam um mapeamento das áreas livres, das áreas de estabilidade e das áreas de instabilidade enzoótica para a babesiose bovina. As publicações disponíveis na literatura nacional apresentam regiões de instabilidade enzoótica (PATARROYO et al., 1982; MADRUGA $\boldsymbol{e t}$ al. 1984; MARTINS et al., 1994). Entretanto, segundo KESSLER et al. (1983), o território brasileiro é uma área de estabilidade enzoótica para a doença, onde os bovinos se encontram naturalmente imunizados contra Babesia.

A babesiose bovina no país é mais freqüentemente encontrada em bezerros. Estudo da doença, no Mato Grosso do Sul, demonstrou sua presença em bezerros com idade inferior a quatro meses (MADRUGA et al., 1986). Situação devido à queda da imunidade passiva a partir do $28^{\circ}$ dia após o nascimento (MADRUGA et al., 1984).

As áreas de estabilidade enzoótica são aquelas em que existe equilíbrio entre imunidade e doença, onde $75 \%$ dos animais com idade acima de 9 meses são portadores de hemoparasitos. Isso significa que a maioria desses animais estão adquirindo a infecção ainda como bezerros (primoinfecção precoce durante a fase mais resistente às plasmoses). Essa infecção vem sendo mantida assintomaticamente nos animais mais velhos através das reinfecções pela manutenção da população de $\boldsymbol{B}$. microplus, infestando os animais durante todo ano e acarretando baixa mortalidade pelas hemoparasitoses em animais adultos.

O número de vetores no meio ambiente, no que diz respeito à taxa de inoculação do hemoparasito, é um importante fator que afeta a epidemiologia. Em áreas endêmicas, onde a população de vetor é alta e presente durante todo o ano, a maioria dos animais jovens são infectados, quando então apresentam resistência natural. Além disso, a incidência sazonal de Babesia spp na hemolinfa de carrapatos pode interferir na taxa de inoculação do parasito. Em áreas onde a ocorrência do $\boldsymbol{B}$. microplus infectado com Babesia é permanente, há um equilíbrio entre o bovino e o parasito, criando uma situação de estabilidade. Nessas áreas, não são esperados surtos da doença e nem de mortalidade em animais adultos, pois eles já são portadores.

Em algumas regiões do Sudeste e do Centro-Oeste, o manejo de carrapatos vem sendo feito adequadamente (MAGALHÃES \& LIMA, 1991), pois os animais, em contato com o vetor, adquirem a infecção nas primeiras semanas de vida, mantendo-se infestados no decorrer dos anos. Para se determinar o perfil de estabilidade/instabilidade de uma região, devem-se avaliar os fatores inerentes ao animal, como por exemplo, a queda de imunidade devido à redução do número de carrapatos e outros que podem estar interagindo no ambiente. Entre eles, raça, idade, variações climáticas, estresse, manejo e tipo de pastagens (ALONSO et al., 1992).

Para evitar o aparecimento de animais doentes em uma área, em função de altas infestações de carrapatos e, conseqüentemente, doses infectantes de babesia maiores, recomenda-se que os rebanhos recebam de 10 a 20 larvas de carrapato/animal/dia (LIMA, comunicação pessoal). Esse número de carrapatos é necessário para inoculação das babesias na manutenção da estabilidade enzoótica em um rebanho. No país, a taxa de infecção dos carrapatos e, conseqüentemente, a taxa de inoculação, é obtida em inúmeras propriedades em que se realiza o controle estratégico. Pode-se considerar também estabilidade enzoótica aquela em que a porcentagem de animais infectados é menor que $20 \%$, onde a população de carrapatos está possivelmente em níveis muito baixos, estando próximo de sua erradicação. Nessas áreas, ocorrem baixas taxas de inoculação, não propiciando a surtos.

Situação altamente indesejável é a que ocorre nas áreas de instabilidade enzoótica, onde a porcentagem de infecção em animais acima de 9 meses está entre 20 e $75 \%$, sendo esses níveis detectados através de testes sorológicos. A primoinfecção é verificada em idade avançada. Ocorrem surtos da doença em animais adultos e, conseqüentemente, altas taxas de mortalidade. Ocorrem flutuações na população de vetores por condições climáticas desfavoráveis, manejo ou medidas de controle dos vetores inadequados (MAHONEY.\& ROSS, 1972).

Alguns fatores influenciam a susceptibilidade dos animais às hemoparasitoses, destacando-se: os animais Bos taurus são mais sensíveis aos carrapatos e assim às hemoparasitoses, enquanto o gado zebu é naturalmente mais resistente; os bovinos jovens são mais resistentes do que os adultos. Essa resistência decorre da presença de anticorpos colostrais, rápida resposta da imunidade celular, maior eritropoese da medula óssea e da presença de hemoglobina fetal nos eritrócitos. Sendo assim, a infecção precoce é importante devido a menor susceptibilidade dos animais jovens que apresentam quadros clínicos menos severos (RISTIC, 1960). A primoinfecção ocorre geralmente entre quatro a seis semanas de vida, sendo que o pique de parasitemia coincide com a queda do volume globular (MADRUGA et al., 1986). Pode ocorrer instabilidade pela presença de fatores imunossupressivos em associação à alta carga parasitária pelo vetor no período. Como causas 
da diminuição do "status" imune, podem-se assinalar a imunidade passiva insatisfatória, o estresse, o estado nutricional, a época do ano, o manejo instituído, periparto e tipo de pastagens. Os fatores climáticos podem ter importância na epidemiologia da babesiose, influenciando a população de carrapatos ou a transmissão do protozoário. A variação sazonal do B. microplus tem sido demonstrada no estado de Minas Gerais (MAGALHÃES \& LIMA, 1991). Deve-se levar em conta que as mudanças na intensidade da população de carrapatos nos bovinos afetam a taxa de inoculação do protozoário no hospedeiro. Uma população de carrapatos deve estar controlada em níveis economicamente viáveis, favorecendo dose infectante ao animal que proporcione capacidade de resposta imunológica anterior ao aumento da parasitemia. Em propriedades com determinados tipos de bezerreiros, onde os animais se encontram permanentemente estabulados, ocorre freqüentemente a presença da doença clínica, logo que esses animais vão a pasto. Práticas de manejos instituídas no sistema de criação como o uso de instalações tipo "Free Stall", onde as vacas ficam estabuladas sem contato com carrapatos, favorecem o aparecimento de surtos quando esses animais são colocados em pastagens infestadas, no período seco. Nesses casos, ocorrem eliminação da infecção assintomática e perda de imunidade. Em áreas endêmicas, os bezerros recebem proteção passiva de anticorpos presentes no colostro, aproximadamente até três meses de idade (JAMES et al., 1985). A proteção pode persistir por até 6 meses de idade para $\boldsymbol{B}$. bovis e de três a quatro meses para B. bigemina. Segundo alguns autores, após a primo-infecção, os animais permanecem sorologicamente positivos por um período de quatro anos para $\boldsymbol{B}$. bovis e, pelo menos, dois a três anos para a B. bigemina (WRIGHT et al., 1990). Quanto ao A. Marginale, esse período é de 8 meses (MAGONIGLE \& NEWBY, 1984). Em temperaturas abaixo de $20^{\circ} \mathrm{C}$, os ovos postos pelas teleóginas não apresentam infecção pelas babesias, em função da inibição da multiplicação desse agente no carrapato. Geralmente, bezerros que nascem em épocas de frio na região Sul adquirem infecção mais tardiamente, na primavera, e no verão ou no outono quando as populações de carrapatos estão maiores. Esse fato, associado à ausência dos fatores que fornecem resistência às babesioses, leva à alta incidência da doença clínica, a partir da primavera, nos animais nascidos no inverno.

\section{Epidemiologia da Anaplasmose}

A infecção por $\boldsymbol{A}$. marginale determina significativas perdas econômicas na pecuária bovina do Brasil (MADRUGA et al., 1984). No Estado de
Minas Gerais, a anaplasmose tem sido considerada uma das doenças de maior importância, constituindo-se em fator limitante à criação de bezerros (RIBEIRO et al., 1983). O organismo pode ser transmitido biologicamente através de carrapatos (AGUIRRE $\boldsymbol{e t}$ al., 1994), mecanicamente via picada de mosquitos e moscas hematófagas (HAWKINS et $\boldsymbol{a l} ., 1982$ ) e congenitamente (RIBEIRO $\boldsymbol{e t}$ al., 1995).

Numa população de animais susceptíveis, principalmente aqueles em processo de premunição ou transportados de áreas indenes e/ou de instabilidade enzoótica, a mortalidade em decorrência da anaplasmose é maior em animais mais velhos (HUNGERFORD \& SMITH, 1997). Os animais mais novos adquirem a infecção e, quando manifestam sintomas clínicos, são mais resistentes do que os adultos. A explicação para isso deve-se ao fato de que animais mais jovens ainda apresentam soro e hemoglobina fetal, o que prejudica parcialmente a multiplicação do agente no sangue e determina uma maior atividade eritropoiética da medula óssea (RISTIC, 1960). Também a presença de anticorpos maternos adquiridos pelo colostro (CORRIER \& GUZMAN, 1977) confere uma imunidade parcial. Dessa forma, animais mais velhos, susceptíveis, tendem a apresentar maiores parasitemias e uma anemia mais severa. Nos animais adultos, a doença apresenta-se de forma aguda ou hiperaguda.

Nas áreas endêmicas, em rebanhos autóctones com manejos extensivos e/ou semiextensivos e alta população de vetores, os animais adquirem o $\boldsymbol{A}$. marginale nos primeiros dias de vida, sendo que o parasita aparece entre 50 a 74 dias de idade. Assim sendo, o equilíbrio é estabelecido precocemente, pois esses animais se infectam logo após o nascimento e, conseqüentemente, apresentam parasitemia moderada (ERIKS et al., 1989). O pique da parasitemia varia de 2 a 13\% (média 7\%) e ocorre de uma a quatro semanas após o aparecimento das primeiras hemácias parasitadas. Nesse período, há remoção somente das hemácias parasitadas que apresentam alterações celulares. Com a evolução da patogenia, aparecem os auto-anticorpos que aderem aos eritrócitos infectados e não infectados, aumentando a fagocitose das hemácias pelos macrófagos, principalmente no baço. Ocorrem diminuição do volume globular e anemia, que podem levar o animal à morte (RISTIC, 1960).

$O$ percentual de animais doentes e a taxa de mortalidade dependerão de algumas condições epidemiológicas, tais como: número de vetores no ambiente, estado nutricional e doenças concomitantes. Recuperando-se da doença, os animais tornamse portadores assintomáticos. Embora esses bovinos sejam portadores assintomáticos da anaplasmose, 
apresentam pouca importância como fonte de infecção para os animais mais novos ou susceptíveis. Nesses portadores adultos, são detectados baixos níveis de parasitos no sangue e os aumentos de parasitemia que esporadicamente apresentam, dificilmente atingem a ordem de $0,3 \%$. Em estudos controlados, constatou-se que a parasitemia mínima no animal para que a transmissão por carrapatos seja eficiente, deve ser 0,3\% (KIESER et al., 1990). Sendo assim, os bezerros parecem ser a principal fonte de infecção do $\boldsymbol{A}$. marginale, mesmo sem a constatação de sinais clínicos, pois eles apresentam parasitemia superior a $0,3 \%$, favorecendo a transmissão do agente infeccioso de animais portadores (bezerros em convalescência) para animais susceptíveis (ZAUGG et al., 1986). Fato esse observado nas imediações dos estábulos de propriedades leiteiras, onde geralmente existem os bezerreiros. Nesses locais, os principais vetores incriminados na transmissão podem ser a mosca dos estábulos, $\boldsymbol{S}$. Calcitrans, e os culicídeos, que são facilmente encontrados.

Em função da disseminação da anaplasmose pelos dípteros hematófagos no Brasil, as transmissões ocorrerão com maior intensidade nas épocas quentes e úmidas do ano, quando a população dos vetores é maior. Animais que nascem em épocas de populações de dípteros muito baixas, como no inverno da região Sul, adquirirão a infecção mais tardiamente. Nessa fase, os bezerros já perderam os fatores naturais que lhes conferem resistência, desenvolvendo assim sinais clínicos da doença.

Os cervídeos são considerados reservatórios naturais de $\boldsymbol{A}$. marginale, porém, essa constatação é de pouca importância epidemiológica no Brasil, uma vez que os próprios bovinos são reservatórios do A. marginale.

\section{Controle}

Os métodos de profilaxia empregados para as hemoparasitoses são: o controle dos vetores, a quimioprofilaxia, a premunição e o uso de vacinas. $\mathrm{O}$ controle de carrapato constitui-se em uma medida de controle da TPB e pode ser implementado em dois níveis: erradicação e controle estratégico. A campanha de erradicação do carrapato B. microplus foi iniciada nos Estados Unidos em 1906 e é mantida atualmente pela vigilância sanitária (RISTIC \& MONTENEGRO-JAMES, 1988). Estudos realizados na Argentina (SIGNORINI \& MATTOS, 1989) e em Porto Rico (CROM, 1992) exemplificam áreas que têm como objetivo a erradicação do carrapato. No Brasil, é utilizado o controle estratégico em determinadas áreas (OLIVEIRA, 1993), mas freqüen- temente, observa-se o uso indiscriminado de produtos carrapaticidas. Com o objetivo de aumentar a produtividade, os pecuaristas têm adotado práticas de manejo como a estabulação e a aquisição de animais com melhor potencial genético. Essas práticas têm contribuído para a proliferação da população de carrapatos e, assim, das áreas de instabilidade enzoótica aos hemoparasitos. Portanto, o carrapato não deve ser erradicado da propriedade, e sim controlado, de forma que os animais sejam parasitados durante todo o ano com infestações baixas, permitindo assim doses infectantes adequadas de Babesia.

O controle de carrapato, associado à imunização de animais susceptíveis, constitui uma medida apropriada de profilaxia dessa hemoparasitose em determinadas áreas de instabilidade enzoótica. Para a anaplasmose, deve-se manter o controle de moscas na propriedade, principalmente nas estações chuvosas, quando a população de dípteros hematófagos é maior, controlando assim as taxas de infecção por A. marginale.

A quimioprofilaxia baseia-se no uso de drogas específicas em doses subterapêuticas. $\mathrm{Na}$ anaplasmose, consiste em 2-4 aplicações de subdoses de tetraciclina $(2-4 \mathrm{mg} / \mathrm{kg} / \mathrm{PV})$, pela via IM, intervaladas de 21 em 21 dias. Esse período é estabelecido de acordo com o período de incubação da doença e pode ser implementada a partir de 30 dias de idade do animal. As subdoses quimioterápicas permitirão ao animal adquirir a infecção sem sinais clínicos ou com sinais brandos. Para a babesiose, tem-se empregado o imidocarb na dosagem de 1$2 \mathrm{mg} / \mathrm{kg} / \mathrm{PV}$, com resultados satisfatórios (KUTTLER \& JOHNSON, 1986), nos bezerros ao serem colocados a pasto. Esse procedimento evita a presença do agente no organismo ou mantém sua população em níveis subclínicos, estabelecendo o estado de portador ao animal. Apresenta a desvantagem de levar a resistência a antibióticos a outros patógenos, como por exemplo a Escherichia coli (HIRSH et al., 1974).

A premunição constitui-se em um método de controle muito utilizado, com a finalidade de promover o desenvolvimento de imunidade contra as hemoparasitoses (BRASIL $\boldsymbol{e t} \boldsymbol{a l} .$, 1982; LIMA, 1991, NOGUEIRA et al., 1991). O processo se baseia na inoculação de sangue de animal portador em animais susceptíveis e com seu subseqüente tratamento usando drogas específicas. Essa medida determina uma proteção à infecção, mesmo que ocorram variações entre amostras das espécies dos hemoparasitos e, em condições tropicais, é provavelmente o procedimento de imunização mais eficaz. Apesar da premunição apresentar alto custo, riscos 
como a disseminação de doenças e a ocorrência da "doença hemolítica do recém-nascido", esses são mínimos se comparados àqueles ocasionados pela introdução de bovinos susceptíveis e não protegidos em áreas enzoóticas (LIMA, 1991).

A premunição moderna consiste na utilização de inóculos padronizados de cada agente (A. marginale, B. bigemina e $B$. bovis), em geral congelados em nitrogênio líquido. Os inóculos são produzidos em bezerros esplenectomizados e o número de parasitas/ml de sangue é quantificado $\left(10^{5}\right.$ a $10^{7}$ hemácias parasitadas) (KESSLER et al., 1987b). Esse número de parasitos inoculados, diretamente dependente da virulência da amostra, torna previsível o período em que os animais apresentarão sinais clínicos e, até mesmo, a intensidade das infecções. Isso facilita e racionaliza os tratamentos, que deverão ser instituídos após a avaliação de quatro parâmetros: temperatura corporal, parasitemia, hematócrito e patogenicidade das amostras utilizadas. A temperatura corporal deve ser determinada duas vezes ao dia, exames de esfregaços de sangue periférico e avaliação do volume globular. A avaliação da resposta imune, através de testes sorológicos, deve ser feita ao final de cada etapa do processo.

Geralmente, o pico febril de 8 a 14 dias após a inoculação deve-se à babesiose. $\mathrm{O}$ pico febril por anaplasmose é esperado 21 a 38 dias após a inoculação. Após a recuperação dos animais, devem ser realizados outras duas ou três inoculações, com a finalidade de reforçar a imunidade adquirida na inoculação anterior. Após a última inoculação, os animais devem ser infestados por carrapatos, para que os bovinos desenvolvam imunidade contra a amostra da propriedade. Esse procedimento torna-se necessário devido à existência de diversidade antigênica entre amostras no país (KESSLER et $\boldsymbol{a l}$., 1987a). Após cada etapa do processo, caso ocorram recidivas, os animais devem ser tratados. Ao término das etapas, os animais podem ser soltos a pasto, porém, esse desafio deve ser gradativo, sendo recomendável o acompanhamento dos animais por alguns dias.

Vários métodos de vacinação têm sido desenvolvidos e estudados em condições de laboratório e de campo, como medidas imunoprofiláticas contra a babesiose bovina. Na maioria deles, utilizase como vacina sangue infectado de animais geralmente esplenectomizados, contendo formas vivas atenuadas (CALLOW \& MELLORS, 1966) ou inativadas (TAYLOR, 1989). Outra linha de pesquisa explora o uso de estágios de Babesia no carrapato (esporozoíto) como um meio de indução de imunidade protetora contra essa parasitose (McELWAIN et al., 1992).
As vacinas atenuadas para $\boldsymbol{B}$. bigemina e B. bovis são usadas, com resultados satisfatórios, em determinados países como: Austrália, Argentina, Uruguai, especialmente nas áreas de instabilidade enzoótica. No Brasil, trabalhos com o isolamento e a atenuação de amostras de campo de B. bigemina e B. bovis foram desenvolvidos inicialmente na EMBRAPA-CNPGC, seguindo-se a metodologia australiana (KESSLER et al., 1987a, 1987b; KESSLER $\boldsymbol{e t} \boldsymbol{a l} .$, 1991). Testes avaliando a patogenicidade e imunogenicidade dessas amostras demonstraram baixa patogenicidade para $\boldsymbol{B}$. bovis, pois não foram observados casos de doença clínica após vacinação. Em relação à $\boldsymbol{B}$. bigemina, essa amostra apresentava relativa virulência, sendo verificada a doença clínica em alguns animais. Nesses testes, foram demonstrados também que as duas amostras eram altamente imunogênicas, protegendo os animais contra posterior desafio. Atualmente, existem uma vacina comercial e outras amostras vacinais com resultados promissores em diferentes centros de pesquisa. Em associação com as amostras atenuadas de Babesia, tem-se utilizado o A. centrale, que confere proteção parcial contra o A. marginale, apresentando bons resultados (KESSLER $\boldsymbol{e t}$ al., 1991).

A irradiação de Babesia foi também uma outra tentativa de desenvolvimento de vacina para o controle da babesiose (WRIGHT, 1990). Entretanto, apesar de evidências de algum grau de proteção contra cepas homólogas e heterólogas, essa linha de estudo não teve continuidade.

Com o advento da tecnologia do DNA recombinante, vários trabalhos têm sido feitos para o desenvolvimento de uma nova geração de vacinas contra a babesiose. O primeiro teste de vacina contra B. bovis, utilizando proteína recombinante, mostrou pequena proteção contra desafio com cepas heterólogas (TIMMS \& BARRY, 1988). Apesar dos trabalhos já realizados apresentarem sucesso limitado, muitos pesquisadores acreditam que a vacina ideal contra babesiose bovina só será produzida através da biotecnologia, seja através da clonagem de genes e expressão de proteínas recombinantes e/ou pela síntese bioquímica de polipeptídeos.

Para a anaplasmose, existem três tipos de vacinas desenvolvidas. A vacina atenuada que utiliza amostra de $\boldsymbol{A}$. marginale (RISTIC et al., 1968), a qual é submetida à indução de mutação, pela exposição à radiação e seleção após duas passagens seriadas em cervídeos e ovelhas. Após aplicação, os animais desenvolvem resposta imunológica humoral e celular (RISTIC \& CARSON, 1977).

No Brasil e em outros países, têm sido feito experimentos com amostra atenuada de $\boldsymbol{A}$. marginale. A imunidade conferida por essa vacina é 
capaz de diminuir as perdas econômicas causadas pela morbidade e/ou mortalidade após um desafio experimental ou natural com amostras virulentas de Anaplasma. O outro tipo é a vacina inativada desenvolvida a partir de sangue de animais previamente inoculados no pique da parasitemia, sendo posteriormente as células sanguíneas lavadas, lisadas e liofilizadas (BROCK $\boldsymbol{e t}$ al., 1965). No Brasil, não têm sido realizados estudos a respeito do emprego dessa vacina e não há autorização de sua comercialização pelas autoridades competentes. E, por último, a imunização através da espécie Anaplasma centrale, que causa infecção branda ao animal, podendo amenizar a severidade da infecção pelo $\boldsymbol{A}$. marginale. $\mathrm{O}$ A. centrale induz uma imunidade parcial contra $\boldsymbol{A}$. marginale e vem sendo usada como vacina heteróloga, em função de sua menor patogenicidade. Essa vacina tem sido usada em vários países e, no Brasil, está sendo difundida pela EMBRAPA e Estado do Rio Grande do Sul (KESSLER et al., 1991).

\section{CONCLUSÃO}

Até o presente momento, vários pesquisadores, tanto no Brasil quanto em outros países, têm buscado novos métodos de controle das hemoparasitoses. Apesar dos muitos avanços alcançados para o desenvolvimento desses métodos, ainda existem alguns obstáculos no controle da TPB. Assim, a carência de estudos epidemiológicos, levando em consideração a interação entre agente-hospedeiroambiente, constitui importante obstáculo para o controle da doença. Nesse sentido, o conhecimento dos fatores de estabilidade e instabilidade que podem estar interagindo no meio, a caracterização das amostras dos hemoparasitos nas regiões fisiográficas do país, bem como a determinação das áreas endêmicas são ferramentas importantes. Os sistemas de criação empregados na pecuária nacional exigem profissionais, a cada dia, com maior conhecimento sobre a TPB e seus determinantes. Além disso, o uso indiscriminado de produtos carrapaticidas e a falta de padronização dos métodos utilizados na premunição exigem atenção, uma vez que os mesmos podem gerar resultados imprevisíveis, até mesmo insatisfatórios.

Na região sudeste, onde a doença é endêmica, a maior incidência é verificada em bezerros até oito meses de idade e em animais adultos que são oriundos de áreas livres de vetores. Portanto, a profilaxia recomendada para a babesiose bovina é o controle adequado do Boophilus microplus. Programas de controle específicos e apropriados devem ser instituídos para cada situação. Há necessidade de estudos dos fatores ambientais que influenciam o desenvolvimento do carrapato, visando a uma redução gradativa da incidência da doença, a fim de alcançar um equilíbrio entre a população de bovinos e um número reduzido de carrapatos livres de infecção (estabilidade enzoótica da TPB). No caso da anaplasmose, além das medidas já citadas, devem-se implementar práticas de manejo adequadas, pois essa enfermidade é facilmente transmitida em vacinações, descornas e castrações. A vacinação com cepas atenuadas deve ser estabelecida de maneira controlada em bovinos susceptíveis à doença, principalmente em adultos, quando esses serão expostos pela primeira vez ao desafio com vetores. Essas medidas são eficientes e econômicas para o controle da TPB na região sudeste do Brasil.

\section{REFERÊNCIAS BIBLIOGRÁFICAS}

AGUIRRE, D.H., GAIDO, A.B., VINABAL, A.E., $\boldsymbol{e} \boldsymbol{t} \boldsymbol{a l}$ Transmission of Anaplasma marginale with adult Booplilus microplus ticks fed as nymphs on calves with different level of rickettsaemia. Parasite, v. 1, p. 405-407, 1994.

ALONSO, M., ARELLANO-SOTA, C., CERESER, V.H. et al. Epidemiology of babesiosis in Latin America and the Caribbean. Revue Science Techonology Off International Epizootiology, v. 11, n. 3, p. 713-733, 1992.

BABES, V. Sur l'hemoglobinurie bacterienne du boeuf. Comptes Rendus Hebdomadaires des Seances de l'Academie des Sciences, v. 107, p. 692-694, 1888.

BRASIL, A.G., MONMANY, L.F., SÁ, et al. Premunição contra a tristeza parasitária a campo. A Hora Veterinária, n. 10, p. $4-8,1982$

BROCK, W.E., KLIEWER, I.O., PERSON, C.C. A vaccine for anaplasmosis. Journal American Veterinary Medical Association, v. 147, p. 948-951, 1965.

CALLOW, L.L., MELLORS, L.J. A new vaccine for Babesia argentina infection prepared in splenectomized calves. Australian Veterinary Journal, v. 42, p. 464-465, 1966.

CORRIER D.E., GUZMAN S. The effect of natural exposure to Anaplasma and Babesia infections on native calves in an endemic area of Colombia. Tropical Animal Health Production, v. 9, n. 1, p. 47-51, 1977.

CROM, R.L. Eradication of Boophilus microplus (Acari: Ixodidae) in Puerto Rico. Annales New York Academic Science, v. 16, n. 653, p. 64-71, 1992.

DE VOS, A.J. Distribution, economic importance and control measures for Babesia and Anaplasma. In: WORKSHOP, ILRAD, Nairobi, Kenya, 1991. Proceedings... T.T. Dolan (Editor), 1992.312 p. p. 3-15.

ERICKS, I.S., PALMER, G.H., McGUIRRE, T.C., et al. Detection and quantitation of Anaplasma marginale in carrier cattle by using a nucleic acid probe. Journal Clinical Microbiology, v. 27, p. 279-284, 1989.

HAWKINS, J.A., LOVE, J.N., HIDALGO, R.J. Mechanical transmission of anaplasmosis by tabanids (Diptera: 
Tabanidae). American Journal Veterinary Reseach, v. 43, p. 732-734, 1982 .

HIRSH, D.C., BURTON, G.C., BLENDEN, D.C. The effect of tetracycline upon establishment of Escherichia coli of bovine origin in the enteric tract of man. Journal Application Bacteriology, v. 37, n. 3, p. 327-333, 1974.

HUNGERFORD L.L., SMITH R.D. Variations in seroprevalence and host factors for bovine anaplasmosis in Illinois Veterinary Research Community., v. 21, n. 1, p. 9-18, 1997.

JAMES, M.A., CORONADO, A., LOPEZ, W., et al. Seroepidemiology of bovine anaplasmosis and babesiosis in Venezuela. Tropical Animal Health Production, v. 17, p. 918,1985

KESSLER, R.H., MADRUGA, C.R., SHENCK, M.A.M., et al. Babesiose cerebral por Babesia bovis (Babes, 1888, Starcovici, 1983) em bezerros do estado do Mato Grosso do Sul. Pesquisa Agropecuária Brasileira, v. 22, p. 1225-1230, 1983.

KESSLER, R.H., MADRUGA, C.R., JESUS, E.F., et al. Isolation of pure strains of Babesia bovis and Babesia bigemina and Anaplasma marginale from cattle in an enzootic area. preliminary test. Pesquisa Agropecuária Brasileira, v. 22, p. 747-752, 1987a.

KESSLER, R.H., SACCO, A.M.S., JESUS, E.F., $\boldsymbol{e t}$ al. Development of live attenuated strains of Babesia bovis and Babesia bigemina: preliminary test. Pesquisa Agropecuária Brasileira, v. 22, p. 1225-1230, 1987 b.

KESSLER, R.H., SASTRE, A.M., MOREIRA, M.A., et al. Experiencias con vacunas vivas atenuadas de Babesia bovis, B. bigemina y Anaplasma centrale conservadas por congelación en Brasil. Revista Cubana de Ciências Veterinárias, v. 22, n. 3, p. 189-196, 1991

KIESER, S.T., ERIKS, I.S., PALMER, G.H. Cyclic rickettsemia during persistent infection of cattle with Anaplasma marginale. Infection and Immunity, v. 58, p. 1117-1119, 1990.

KUTTLER, K.L., JOHNSON, L.W. Chemoprophylactic activity of imidocarb, diminazene and oxytetracycline against Babesia bovis and B. bigemina. Veterinary Parasitology, v.21, n. 3, p. $107-118,1986$

LIMA, J.D. Premunição: uma alternativa para o controle da tristeza parasitária, São Paulo, SP, 1991. In: SEMINÁRIO BRASILEIRO DE PARASITOLOGIA VETERINÁRIA. São Paulo, 22-26 de setembro, 1991. Anais... São Paulo, 1991. 156 p. p. $39-43$.

MADRUGA, C.R, AYCARDI, E, KESLLER, R.M, et al Níveis de anticorpos anti-Babesia bigemina e Babesia bovis em bezerros da raça Nelore, Ibagé e cruzamentos de Nelore Pesquisa Agropecuária Brasileira, v.19, p.1163-1168, 1984.

MADRUGA, C.R., BERNE, M.E.A., KESSLER, R.H., et al. Diagnóstico da tristeza parasitária bovina no estado do Mato Grosso do Sul: inquérito de opinião. Ministério Agricultura EMBRAPA - CNPGC, 1986. 32p. Circular Técnica, n.18.

MAGALHÃES, F.E.P., LIMA, J.D. Controle estratégico do Boophilus microplus (Canestrini, 1887) (Acarina. Ixodidae) em bovinos da região de Pedro Leopoldo, Minas Gerais, Brasil. Arquivo Brasileiro Medicina Veterinária Zootecnia, v. 43, n. 5, p. 423-431, 1991.
MAGONIGLE, R.A., NEWBY, T.J. Response of cattle upon exposure to Anaplasma marginale after elimination of chronic carrier infections. American Journal Veterinary Research, v. 45, n. 4, p. 695-697, 1984.

MAHONEY, D.F., ROSS, D.R. Epizootiological factors in the control of bovine babesiosis. Australian Veterinary Journal, v. 48 , n. 5 , p. $292-298,1972$.

MARTINS, J.R., CORREA, B.L., CERESES, V.H., et al. Some aspects of the epidemiology of Babesia bovis in Santana do Livramento, southern Brazil. Brazilian Journal Veterinary Parasitology, v. 3, n. 2, p. 75-78, 1994.

McELWAIN, T.F., MISHRA, V.S., STEPHENS, E.B. Development of an antigenically defined vaccine against Babesia bigemina. In: Recent developments in the control of anaplasmosis, babesiosis and cowdriosis. In: WORKSHOP HELD AT ILRAD, 1991, Kenya. Proceedings... Nairobi: DOLAN, T.T. ILRAD, 1992. p. 105-112.

NOGUEIRA, F.R.C., MASSARD, C.L., BARREIRA, J.D. Tristeza parasitária bovina. Epidemiologia, sinais clínicos, diagnóstico, medidas de controle e profilaxia. Rio de Janeiro: Ministério da Agricultura, EMBRAPA - PESAGRO, 1991. n. 12, 14 p. Circular Técnico.

OLIVEIRA, P.R. Controle estratégico do Boophilus microplus (Canestrini, 1887) em bovinos de propriedades rurais dos municípios de Lavras e Entre Rios de Minas-MG. Belo Horizonte - MG, 1993. 97p. Dissertação (Mestrado em Medicina Veterinária) - Curso de Pós-graduação em Medicina Veterinária, Universidade Federal de Minas Gerais, 1993.

PATARROYO, J.H., VARGAS, M.I., BICUDO, P.L. Description of lesions in cattle in a natural outbreak of Babesia bovis infection in Brazil. Veterinary Parasitology, v. 11, n.4, p. 301-308, 1982.

RIBEIRO, M.F.B., PATARROYO, J.H., FARIA, J.E. Inquérito de opinião com criadores da Zona da Mata do estado de Minas Gerais. I. Alguns fatores associados com a mortalidade de bezerros. Arquivo Brasileiro Medicina Veterinária Zootecnia, v. 35, p. 547-556, 1983.

RIBEIRO, M.F.B., LIMA, J.D., GUIMARÃES, A.M., $\boldsymbol{e} \boldsymbol{t} \boldsymbol{a l}$. Transmissão congênita da anaplasmose bovina. Arquivo Brasileiro Medicina Veterinária Zootecnia, v. 47, p. 297304, 1995.

RISTIC, M. Anaplasmosis. Advances in Veterinary Science., v. 7, p. 111-192, 1960.

RISTIC, M., CARSON, C.A. Methods of immunoprophylaxis against bovine anaplasmosis with emphasis on use of the attenuated Anaplasma marginale vaccine. Advances in Experimental Medical Biology, v. 93, p. 151-188, 1977.

RISTIC, M., MONTENEGRO-JAMES, S. Immunization against Babesia. In: RISTIC, M. Babesiosis of domestic animals and man. New York: CRC, 1988. p.131-142.

RISTIC, M., SIBINOVIC, S., WELTER, C.J. An attenuated Anaplasma marginale vaccine. Proceeding VS Livestock Saint Association, v. 72, p. 56-69, 1968.

SIGNORINI, A.R., MATTOS, C.E. Main factors in the history of tick eradication in the Argentine Republic -social, economic and legal aspects. In: THE EXPERT CONSULTATION ON THE ERADICATION OF TICKS, WITH SPECIAL REFERENCE TO LATIN AMERICA, EDITED BY FAO, Rome, 1989. Proceedings... Rome, 1989. p. 28-44. 
SMITH, T., KILBORNE, F.L. Investigations into the nature, causation and prevention of Texas or Southern cattle fever. US Department of Agriculture Bur Animal Industry Bulletin, v. 1, p. $7-269,1893$

TAYLOR, S.M. Babesia vaccines attenuated by blood passage and irradiation. In: WRIGHT, I. Veterinary protozoan and hemoparasite vaccines. New York: CRC Press, 1989. p. 43-

THEILER, A. Gallsickness of imported cattle and protection against the disease. Agriculture Journal United American South Africa, v. 3, n. 1, 1910.

TIMMS, P., BARRY, D.N. Failure of a recombinant Babesia bovis antigen to protect cattle against heterologous strain challenge. Research Veterinary Science, v. 45, p. 267-269, 1988.

WRIGHT, I.G. Immunodiagnosis and immunoprophylaxis against the haemoparasites Babesia sp and Anaplasma sp in domestic animals. Revue Science Technology Off International Epizootiology, v. 9, n. 2, p. 345-356, 1990.

ZAUGG, J.L., STILLER, D., COAN, M.E., LINCOLN, S.D Transmission of Anaplasma marginale Theiler by males Dermacentor andersoni Stiles fed on an Idaho field infected, chronic carrier cow. American Journal Veterinary Reseach, v. 47 , p. $2269-2271,1986$

Ciência Rural, v. 30, n. 1, 2000. 